\title{
Réparer le monde, ce qu'il en reste
}

Éditorial

Pierre-Olivier Dittmar et Yann Philippe Tastevin

\section{OpenEdition}

Journals

Édition électronique

URL : https://journals.openedition.org/tc/7771

DOI : $10.4000 /$ tc. 7771

ISSN : 1952-420X

Éditeur

Éditions de l'EHESS

\section{Édition imprimée}

Date de publication : 31 octobre 2016

Pagination : 10-13

ISBN : 9782713225291

ISSN : $0248-6016$

Référence électronique

Pierre-Olivier Dittmar et Yann Philippe Tastevin, « Réparer le monde, ce qu'il en reste », Techniques \& Culture [En ligne], 65-66 | 2016, mis en ligne le 31 octobre 2019, consulté le 29 septembre 2022. URL http://journals.openedition.org/tc/7771 ; DOI : https://doi.org/10.4000/tc.7771 


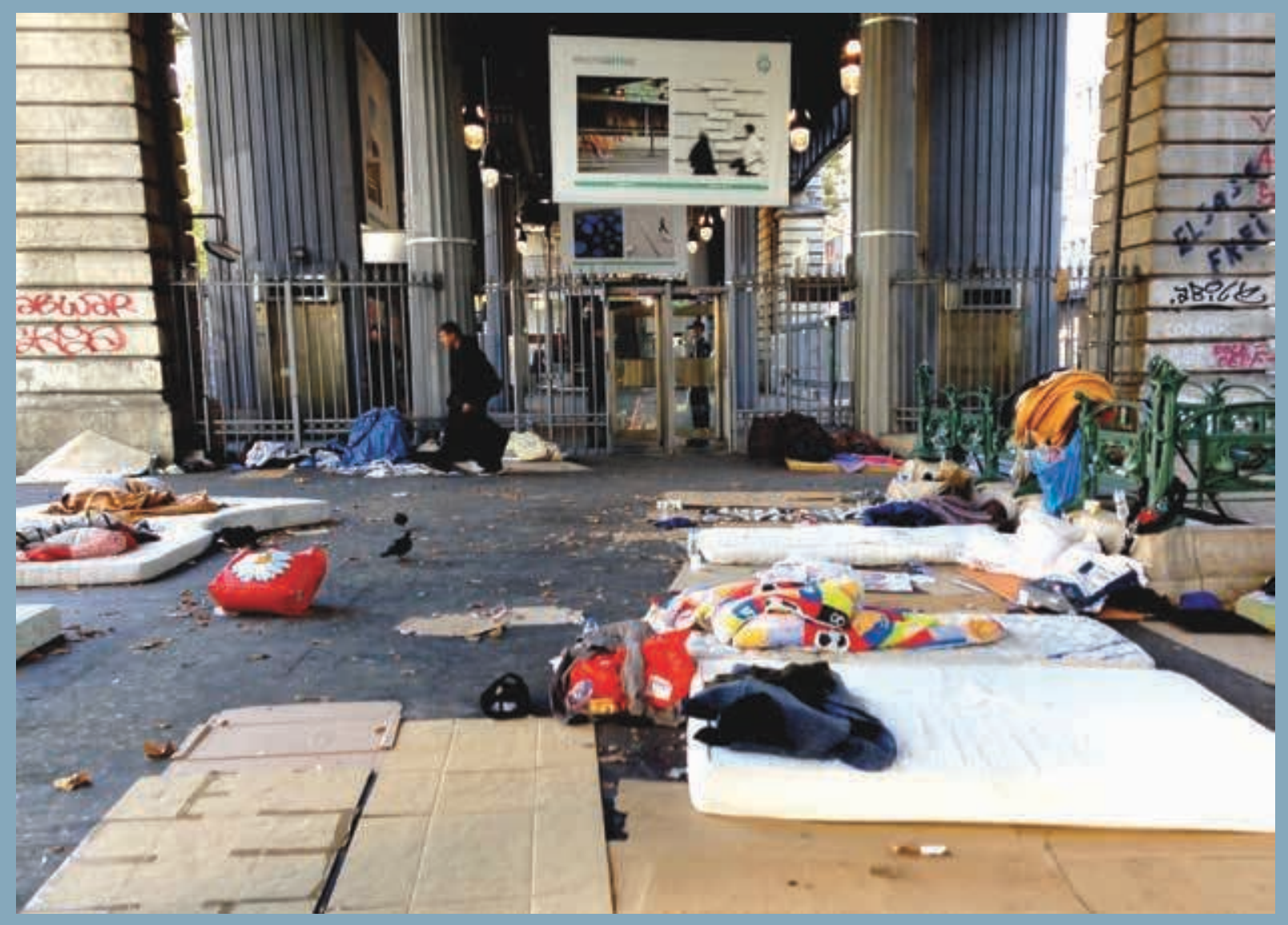




\section{Éditorial}

\section{Réparer le monde, ce qu'il en reste}

Ce numéro double de TechniquesE Culture est singulier en tous points: pendant près de cinq ans, il a nécessité la coopération et la bonne volonté de huit personnes, de deux institutions -l'EHESS et le MUCEM-, donné lieu à un séminaire et à de nombreuses rencontres. L'objet final regroupe presque 50 contributions et une ouverture vers l'international sans précédent avec des articles venant de 16 pays dont une bonne part est accessible en version bilingue, française et anglaise. Ce numéro, reflet d'accélérations et de stases, d'enthousiasmes intellectuels et de difficultés matérielles liés au contexte éditorial tourmenté des sciences humaines, est un exemple abouti de la refonte de la revue que nous destinons à des lectorats divers, associant plusieurs formats d'écriture (papier et électronique) aussi exigeants du point de vue de la forme que du contenu. Il constitue une étape importante dans la vie de la revue et marque l'aboutissement de l'important travail de refonte mené par Frédéric Joulian au cours de dix années d'un engagement total à la direction de Techniques\&Culture. Nous souhaitons ici témoigner de notre gratitude pour le remarquable projet intellectuel et formel qu'il a su mettre en place et que nous nous engageons désormais à porter.

Exceptionnel, ce numéro l'est aussi par l'expérience partagée d'une aventure éditoriale et d'un projet d'exposition lancé par Denis Chevallier au MUCEM sur l'économie des déchets en Méditerranée, intitulée «Vies d'ordures » (prévue de mars à septembre 2017). Ce rapprochement organisationnel et intellectuel entre le département de la recherche du MUCEM et la revue se développe depuis plusieurs années et s'est concrétisé à l'occasion d'un workshop international impliquant Techniques\& Culture, le Centre Norbert Elias et le Musée en novembre 2014, et engageant la pollinisation croisée d'un projet éditorial et muséographique. La façon de travailler à la revue -avec un comité de rédaction et des experts qui organisent des rencontres scientifiques au cours desquelles les acteurs se confrontent et échangent avant de passer à l'écriture-, ou au MUCEM - qui lance un séminaire exigeant et ouvert à tous afin de nourrir les concepts, 
méthodes et contenus de l'exposition - a permis d'éprouver un nouveau dispositif de travail commun. Les enjeux heuristiques et muséographiques d'une revue et d'un musée diffèrent dans leurs modalités de cadrage ou de mise en forme, mais peuvent aussi se rejoindre sur les dimensions politiques, philosophiques ou esthétiques.

Ce numéro est exceptionnel, enfin, par la diversité d'approches présente au sein d'un même volume. Tel était bien l'enjeu de ce projet: courir le risque d'une hétérogénéité extrême pour mieux rentre compte des variations d'échelle et de problématiques d'une question globale. De fait, les écarts sont considérables, et les contributions témoignent aussi bien des vertiges cosmiques et océaniques provoqués par des amoncellements de déchets, que de l'intimité du deuil, de la fragilité d'individus ayant perdu leur enfant, leur outil de travail, et qui chacun à leur façon, essayent de réparer leur monde.

Penser dans le même temps la relégation des objets et leur réappropriation met les chercheurs au cour de la dynamique sociale. De fait, chaque séparation, chaque mise à l'écart d'un objet vers le monde du sale et du déchet crée ou renforce une frontière symbolique, et consolide l'idée de ce que l'on sait être propre, utile, légitime; mais une telle démarche de structuration de l'ordre catégoriel par essence conservateur, possède un envers occulté et pourtant fertile. Presque instantanément, le changement de statut de ces objets devenus déchets ouvre le champ des possibles et autorise des réemplois situés en travers de l'ordre du monde: en un mot, ces objets déchets permettent plus que d'autres la construction de nouvelles catégories. Ce mouvement avant et arrière, de relégation et de création, qui met les objets et les hommes en mouvement, fait des restes et des déchets des sujets privilégiés pour qui s'intéresse à l'anthropologie et à l'histoire des devenirs. Penser les restes et les déchets comme le font les auteurs de ce numéro, c'est lutter pratiquement contre l'hypocrite processus d'invisibilisation auxquels ils sont soumis, un travail qui nous invite aussi, à un niveau plus individuel, à abandonner une impossible posture de séparation et de contrôle vis-à-vis du monde. C'est penser ensemble par quelles techniques on rend supportable et fertile la dissémination à travers la terre et la mer de fragments de notre vie, comment on pense l'usage par d'autres mains, sur d'autres corps, d'habits que l'on a portés, d'objets avec lesquels on a vécu et travaillé. C'est en somme penser les techniques par lesquelles on rend possible une continuité matérielle jamais totalement maîtrisée avec le monde. 


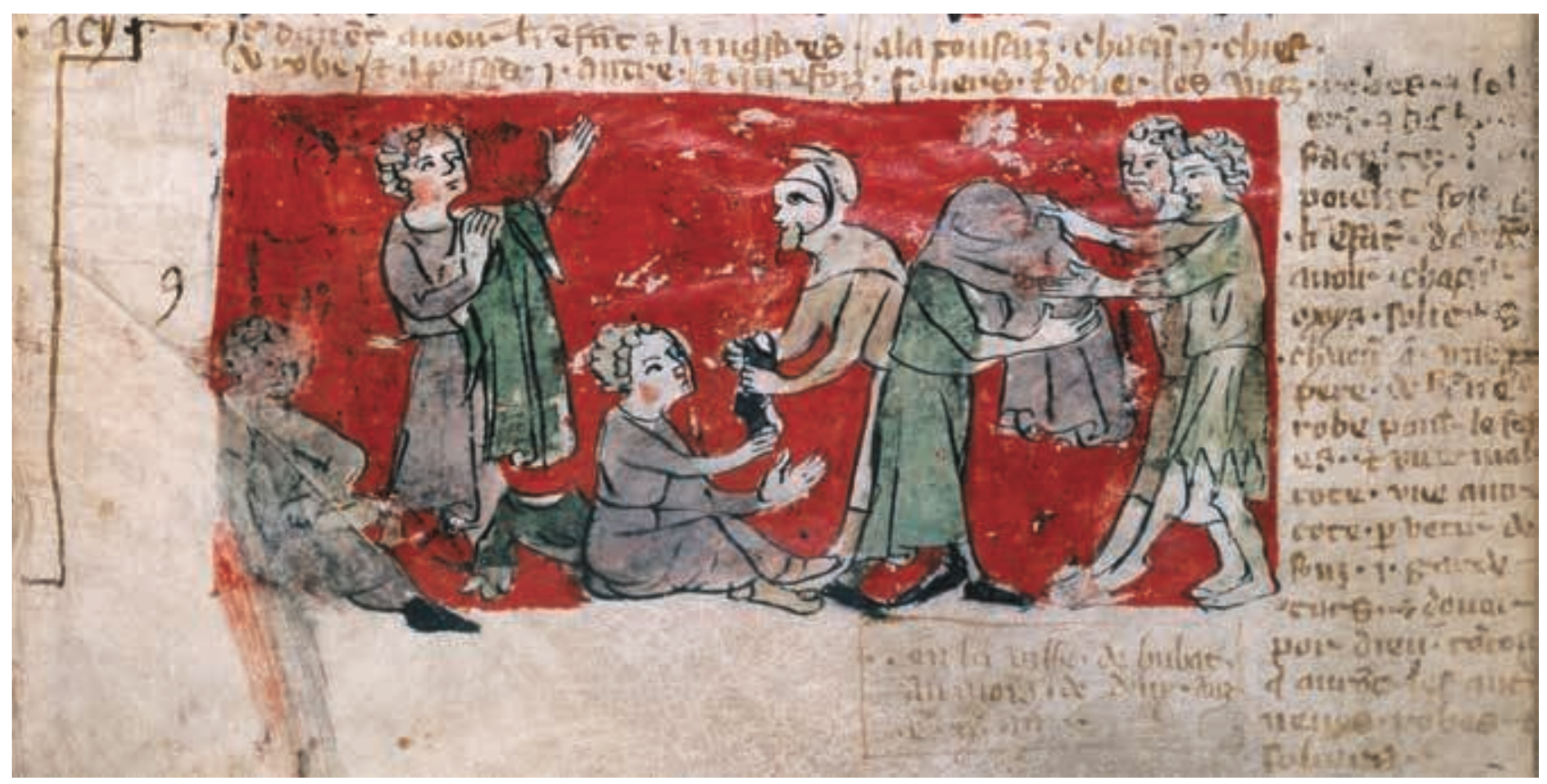

1. Au milieu du xive siècle., les collégiens de la montagne Sainte Geneviève à Paris doivent donner deux fois par an (à la Toussaint et à Pâques) certains de leurs vieux habits à des pauvres.

\section{Iconographie}

Image d'ouverture. Ce qu'il reste d'un camp d'exilés, expulsés le 25 août 2016 au métro Jaurès, à Paris. (c) P.-O. Dittmar.
1. Statuts du collège de Huban, Archives Nationales, AE-II_408(MM406)fo7recto. (C) Domaine public.

\section{Pour citer cet article}

Dittmar, P.-O. \& Y.-P. Tastevin 2016 «Éditorial. Réparer le monde, ce qu'il en reste», TechniquesECulture 65-66 «Réparer le monde. Excès, reste et innovation», p. 10-13. 